\title{
Synthesis and Characterization of Calcium Derivative Combined with High-Surface-Area Activated Carbon Composites for Fine Toxic Gas Removal
}

\author{
Yonrapach Areerob*, Dinh Cung Tien Nguyen*, Biswas Md Rokon Dowla*, \\ Hyuk Kim**, Je-Woo Cha**, and Won-Chun $\mathrm{Oh}^{* * \dagger}$ \\ *Department of Advanced Materials Science \& Engineering, Hanseo University, Seosan 31962, Korea \\ **Carbontec Co., Eumsung 27657, Korea
}

(Received June 7, 2018; Revised June 26, 2018; Accepted June 27, 2018)

\begin{abstract}
Highly toxic gases such as hydrogen sulfide $\left(\mathrm{H}_{2} \mathrm{~S}\right)$, carbon dioxide $\left(\mathrm{CO}_{2}\right)$, and ammonia $\left(\mathrm{NH}_{3}\right)$ are generated by both nature and human activities and affect human health. In this research, activated carbon combined with $\mathrm{Ca}(\mathrm{OH})_{2}$ and $\mathrm{CaCO}_{3}\left(\mathrm{AC}_{-\mathrm{CO}}\right.$ and AC-CC, respectively) were fabricated and applied in absorbing toxic gases from air pollutants. Activated charcoal powder was compressed in the form of pellets and used in the designated conditions. The optimum operating conditions and material properties, such as adsorption capacity, effect of weight ratio of the mixture, and hardness, have been investigated after combining with the calcium derivative. The good performance exhibited in this study suggests that this material is expected to be an effective and economically viable adsorbent for $\mathrm{NH}_{3}, \mathrm{CO}_{2}$, and $\mathrm{H}_{2} \mathrm{~S}$ removal from the air system.
\end{abstract}

Key words : Activated carbon, Toxic gas, Calcium derivative, Absorption

\section{Introduction}

$\mathrm{T}$ he release of anthropogenic toxic pollutants into the atmosphere caused by chemical reactions, the leakage of hazardous industrial gases, as well as the products from combustion reactions, are global risks that are of increasing concern. Common hazardous compounds such as $\mathrm{NO}_{\mathrm{x}}, \mathrm{SO}_{\mathrm{x}}$, $\mathrm{CO}_{2}, \mathrm{H}_{2} \mathrm{~S}$, and $\mathrm{NH}_{3}$, have an adverse impact on human health, and can even cause death. Therefore, it is highly urgent to find an effective way to dispose toxic substances. In this research, we selected three common toxic gases, hydrogen sulfide $\left(\mathrm{H}_{2} \mathrm{~S}\right)$, carbon dioxide $\left(\mathrm{CO}_{2}\right)$, and ammonia $\left(\mathrm{NH}_{3}\right) . \mathrm{H}_{2} \mathrm{~S}$ is a corrosive, poisonous, and odorous gas. $\mathrm{NH}_{3}$ is another contaminant that is widely used in chemical and pharmaceutical industries for various applications, such as a fermentation agent, cleaner, and fertilizer. $\mathrm{CO}_{2}$ is involved in the formation of photochemical smog and acid rain, which are major threats to the environment and human health. Among the many sources of air pollution, particulate matter $(\mathrm{PM})$ is the one most generally noticed by the public. Particles with diameter $<2.5 \mu \mathrm{m}\left(\mathrm{PM}_{2.5}\right)$ have the ability to bind toxic compounds. Highly porous materials are a class that have received a lot of attention owing to their special structures, and may play an important role in the disposal of toxic substances. Moreover, there are various types of purification techniques used for the removal of gas compounds

\footnotetext{
Corresponding author: Won-Chun Oh

E-mail : wc_oh@hanseo.ac.kr

Tel : +82-41-660-1337 Fax : +82-41-688-3352
}

in the air-treatment industry. These treatment techniques include air stripping, ${ }^{1,2}$ adsorption to activated carbon (AC), ${ }^{3)}$ and ozonation. ${ }^{4}$

Activated carbon is a term used to refer to carbon-rich materials that contain well-built internal pore structures. They can be used as absorbent materials because of their higher porosities. Moreover, a wide range of chemical functional groups present on the surface of AC makes it a versatile material that has numerous applications involving activation agents such as $\mathrm{Na}_{2} \mathrm{SO}_{4}, \mathrm{H}_{3} \mathrm{PO}_{4}, \mathrm{ZnCl}_{2}, \mathrm{KOH}$, $\mathrm{CaCO}_{3}$, and $\mathrm{Ca}(\mathrm{OH})_{2} \cdot{ }^{5-7)}$

Activated carbons have been globally recognized as the oldest, widely used, and most popular adsorbent in water and air purification industries.

Calcium carbonate $\left(\mathrm{CaCO}_{3}\right)$, which is abundant in nature and exhibits good biodegradability and biocompatibility, is considered to be one of the most promising candidates for application in air treatment. ${ }^{8)}$ One of the widely applied strategies is to introduce organic additives and templates with functionalized patterns. Owing to the higher solubility of $\mathrm{CaCO}_{3}$ and precipitation transformation properties, bonding was observed between $\mathrm{CaCO}_{3}$ and some heavy metal carbonates. This can effectively adsorb gases and toxic elements from atmospheric and aqueous environments. Yu reported high removal capacities of $1028.21 \mathrm{mg} \mathrm{g}^{-1}$ for $\mathrm{Pb}^{2+}$ and $514.62 \mathrm{mg} / \mathrm{g}$ for $\mathrm{Cd}^{2+}$ within $2 \mathrm{~h}$ by using polyacrylic acid stabilized amorphous $\mathrm{CaCO}_{3}$ nanoparticles. ${ }^{9)}$ Moreover, the removal of toxic gas by using $\mathrm{AC}$ with $\mathrm{CaCO}_{3}$ has been limited to a few studies.

The alkaline earth metal hydroxide $\mathrm{Ca}(\mathrm{OH})_{2}$ represents a 
fine example of multifunctional compounds having the widest range of technological and industrial applications. The elements comprising $\mathrm{Ca}(\mathrm{OH})_{2}$ are widely available, low cost, and non-toxic. Hydrogen and oxygen are the most abundant elements in the universe. Because of the possibility of synthesis by inexpensive and green methods, these materials can be chemically tuned with predesigned functional properties and, therefore, offer very high promise for future applications, e.g., biomedicine, electronic devices, solar energy, gas sensing, etc. ${ }^{10}$

The objective of this study was to elucidate the adsorption properties of $\mathrm{NH}_{3}, \mathrm{CO}_{2}$, and $\mathrm{H}_{2} \mathrm{~S}$ on $\mathrm{AC}$ surfaces modified with $\mathrm{Ca}(\mathrm{OH})_{2}$ and $\mathrm{CaCO}_{3}$ by adsorption. The most important adsorption conditions that affect the adsorption process were also investigated. The adsorption behavior of toxic gases on modified AC can be considered to be mainly monolayer adsorption, and is related to the chemical functional groups on the surface of carbon, which have been identified by iodine absorption, BET, etc.

\section{Experimental Procedure}

\subsection{Synthesis of AC modified with $\mathrm{Ca}(\mathrm{OH})_{2}$ or $\mathrm{CaCO}_{3}$ (AC-CO and AC-CC) pellets}

Activated carbon (YP50F, high surface area, Japan) was dissolved in DI water at room temperature to yield a solution to which was added differing amounts of $\mathrm{Ca}(\mathrm{OH})_{2}$ or $\mathrm{CaCO}_{3}$. After that, the mixed solution was magnetically stirred for $5 \mathrm{~h}$. The mixed samples were first dried in an air convection oven at $100^{\circ} \mathrm{C}$ for $6 \mathrm{~h}$.

About $1.5 \mathrm{~g}$ of the raw material were placed between the pistons in a dice and a mechanical pressure $\mathrm{P}$ was applied on them for 1 min by using an oil hydraulic machine. The pressure ranged from 0 to $98.1 \mathrm{MPa}$. After compression, the raw material ejected from the dice was in the form of a columnar pellet. ${ }^{11)}$

\subsection{Characterization}

\subsubsection{Sample characterization}

The specific surface areas of the AC samples were determined by $\mathrm{N}_{2}$ adsorption (at $-196.15^{\circ} \mathrm{C}$ ), using a surface analyzer (Quantachrome Inst., Nova 2200e). The total pore volume $\left(\mathrm{V}_{\mathrm{t}}\right)$ was calculated from the amount of $\mathrm{N}_{2}$ vapor adsorbed at the relative pressure of 0.95 . The total surface area $\left(\mathrm{S}_{\mathrm{t}}\right)$ was calculated using the BET equation in the relative pressure range $0.05-0.35$. The limits between micro and mesopores and meso and macropores were taken following the IUPAC nomenclature. The Barrett-Joyner-Halenda method was used to calculate the mesopore size distribution.

The mechanical strength characteristics of the ACs prepared were determined according to ASTM D4179 and D6175, compliant for extruded pellet crushing strength, and according to ASTM 7084-04 for bulk crushing strength by using the Crush-BK instrument. The density was determined according to ASTM D2854-09.

\subsubsection{Removal efficiencies of $\mathrm{NH}_{3}, \mathrm{CO}_{2}$, and $\mathrm{H}_{2} \mathrm{~S}$}

The concentrations of $\mathrm{NH}_{3}, \mathrm{CO}_{2}$, and $\mathrm{H}_{2} \mathrm{~S}$ determined by the bypass line were used as the respective inlet concentrations. The $\mathrm{NH}_{3}, \mathrm{CO}_{2}$, and $\mathrm{H}_{2} \mathrm{~S}$ concentrations determined by the flue gas outlet (c) were used as the respective outlet concentrations (each experimental cycle was $30 \mathrm{~min}$, and the average concentrations within this period were used as the outlet concentrations). The removal efficiencies of $\mathrm{NH}_{3}, \mathrm{CO}_{2}$, and $\mathrm{H}_{2} \mathrm{~S}$ can be calculated by Eq. (1):

Gas removal efficiency $\left.\left.=\left(\mathrm{C}_{\text {in }}-\mathrm{C}_{\text {out }}\right) / \mathrm{C}_{\text {in }}\right)\right) \times 100(\%)$,

where $\mathrm{C}_{\text {in }}$ represents the inlet concentrations of $\mathrm{NH}_{3}, \mathrm{CO}_{2}$, and $\mathrm{H}_{2} \mathrm{~S}$ in the gas; and $\mathrm{C}_{\text {out }}$ represents the outlet concentrations of $\mathrm{NH}_{3}, \mathrm{CO}_{2}$, and $\mathrm{H}_{2} \mathrm{~S}$ in the gas. ${ }^{12)}$

$\mathrm{NH}_{3}$ gas removal efficiency: (1) In the experiment for measuring the fixed bed adsorption capacity, standard harmful gas of a certain concentration was passed through a column packed with an adsorbent for its adsorption, and was periodically manufactured and sold at the gas outlet by GASTEC (Japan). The standard gas detection tube of measuring range dependent on the gas type (e.g., 1 to $240 \mathrm{ppm}$ of $\mathrm{H}_{2} \mathrm{~S}$ and 3 to $10 \mathrm{ppm}$ of $\mathrm{NH}_{3}$ can be measured) was used, and the breakthrough point was determined.

$\mathrm{H}_{2} \mathrm{~S}$ gas removal efficiency: In a fixed bed adsorption test, the standard obnoxious gas passing through the column filled with the adsorbent was adsorbed, periodically measured at the gas outlet depending on the gas type manufactured and sold by GASTEC (e.g., 1 to $240 \mathrm{ppm}$ of $\mathrm{H}_{2} \mathrm{~S}$ and 3 to $10 \mathrm{ppm}$ of $\mathrm{NH}_{3}$ can be measured in $4 \mathrm{~L}$ ), and the breakthrough point was determined.

\subsection{3. $\mathrm{CO}_{2}$ adsorption}

The adsorption capacity of the produced AC was determined using a Setaram Setsys evolution thermogravimetric analyzer. In the adsorption experiment, $150 \mathrm{mg}$ of the $\mathrm{AC}$ sample were placed in the analyzer, heated to $100^{\circ} \mathrm{C}$ in nitrogen atmosphere at the flow rate of $60 \mathrm{~mL} / \mathrm{s}$, and held at that temperature for $20 \mathrm{~min}$. The temperature was then set at the desired adsorption temperature and dried $\mathrm{CO}_{2}(99.85$ vol.\%) was introduced at the flow rate of $60 \mathrm{~mL} / \mathrm{s}$ for $\mathrm{CO}_{2}$ adsorption. After the adsorption stage, the gas was switched to pure $\mathrm{N}_{2}$ flowing at the rate of $60 \mathrm{~mL} / \mathrm{s}$ and desorption was performed (Fig. 1). Adsorption capacity, measured in $\mathrm{mL}$ $\mathrm{CO}_{2} / \mathrm{g} \mathrm{AC}$, was used to evaluate the adsorbent. ${ }^{13)}$

Removal efficiency by TPD: The column containing the sample was saturated with $\mathrm{CO}_{2}$, and all the gas physically adsorbed on the surface was removed by He, before the temperature was raised to $800^{\circ} \mathrm{C}$ to detect the amount of desorbed gas by using a thermal conductivity detector (TCD) that measured the converted signal.

Low-temperature adsorption method: For saturation adsorption, adsorption (3-4 h) of $\mathrm{CO}_{2}$ at low temperature $\left(-5-7^{\circ} \mathrm{C}\right)$ and measurement $\left(2-5^{\circ} \mathrm{C}\right)$ at room temperature were performed to remove the supersaturated $\mathrm{CO}_{2}(\mathrm{~m} 1)$; measurement $(\mathrm{m} 2)$ at $700^{\circ} \mathrm{C}$ (removal) was carried out to determine the amount of physically and chemically adsorbed 


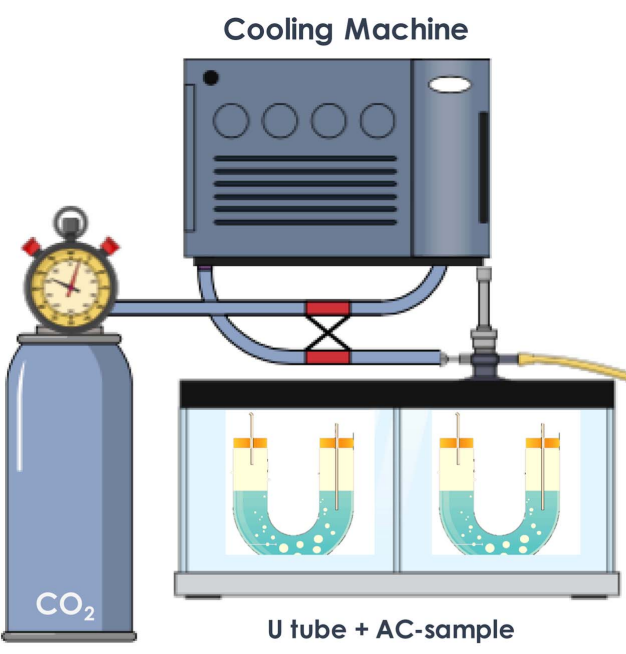

Fig. 1. Carbon dioxide adsorption procedure.

$\mathrm{CO}_{2}$ after the measurement. The amount of $\mathrm{CO}_{2}$ adsorbed $=$ $\mathrm{m} 1-\mathrm{m} 2$.

\subsubsection{Pressure drop}

Pressure loss: P1: Initial operating pressure, P2: Pressure

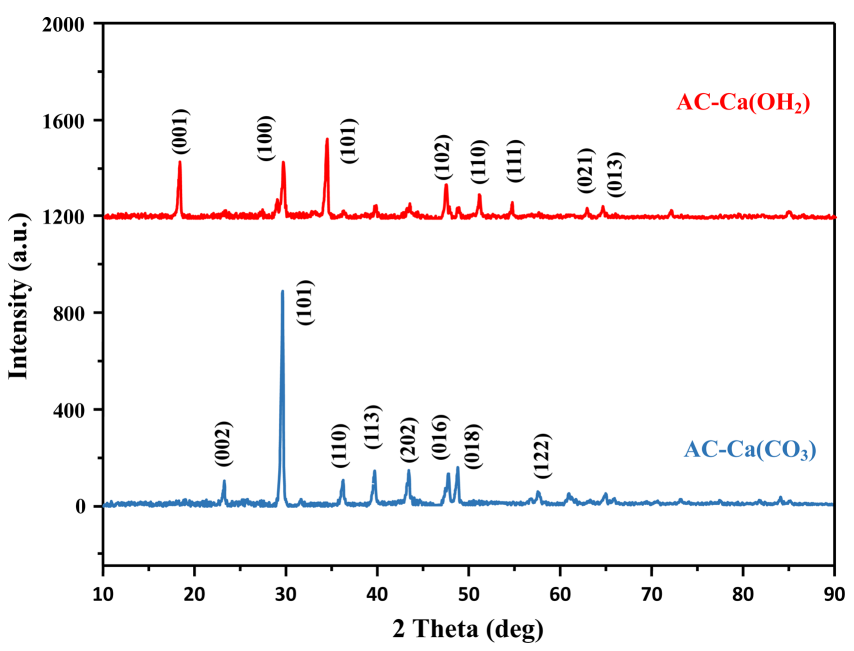

Fig. 2. XRD patterns of activated carbons modified with $\mathrm{Ca}(\mathrm{OH})_{2}$ and $\mathrm{CaCO}_{3}(\mathrm{AC}-\mathrm{CO}$ and $\mathrm{AC}-\mathrm{CC})$.

after passing through one tube after filling the pellet, P3: Pressure after filling two pellets, P1 - P2: Pressure loss (2): P1 - P3, Pressure gauge (digital type): LUTRON ELECTRONIC ENTERPRISE CO., LTD (Model: PS-9302), and Pressure sensor model: PS-100-2BAR.
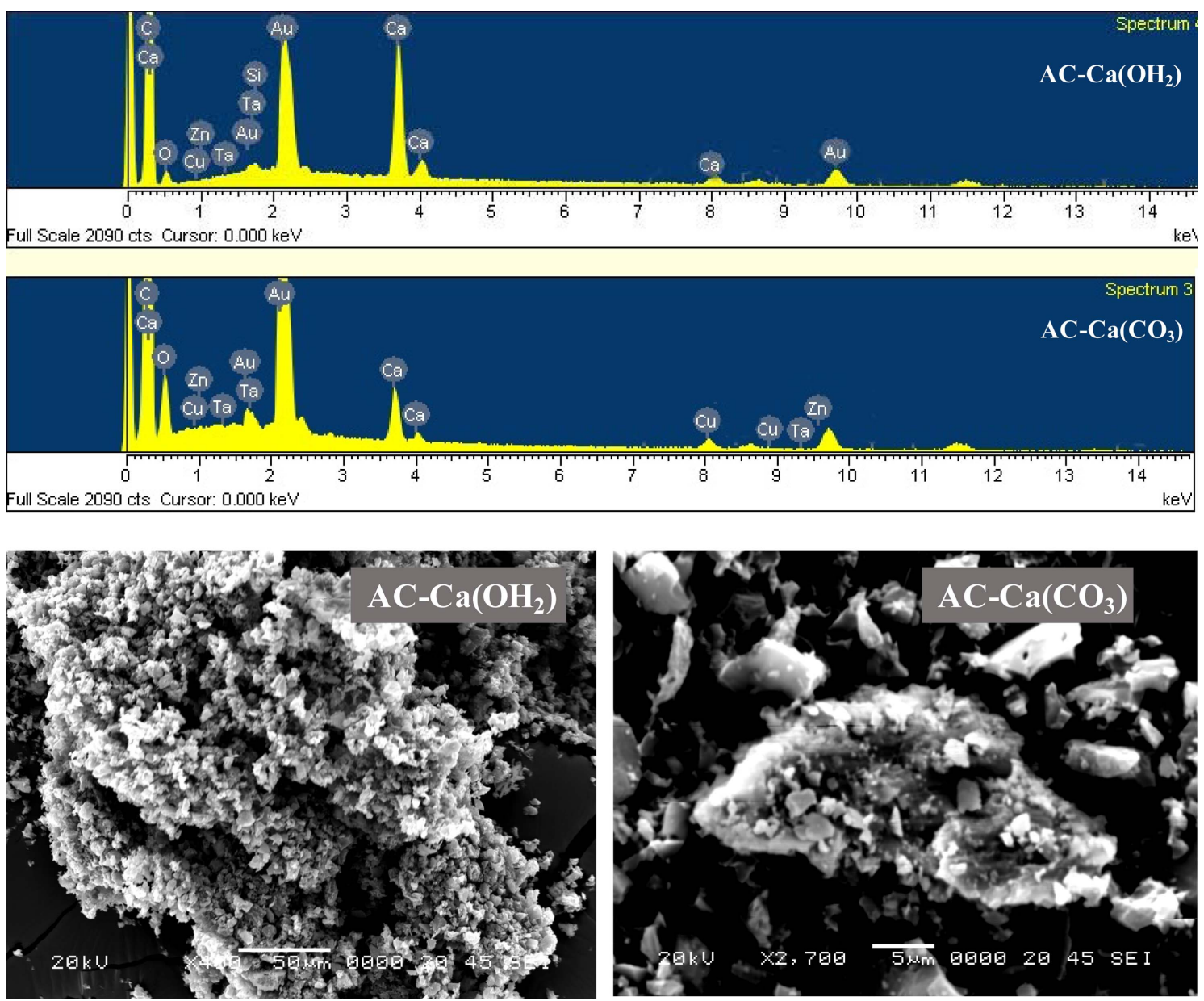

Fig. 3. EDX and SEM images of activated carbons modified with $\mathrm{Ca}(\mathrm{OH})_{2}$ and $\mathrm{CaCO}_{3}(\mathrm{AC}-\mathrm{CO}$ and $\mathrm{AC}-\mathrm{CC})$. 


\section{Results and Discussion}

\subsection{Characterization}

Preliminarily, the ACs modified with $\mathrm{Ca}(\mathrm{OH})_{2}$ and $\mathrm{CaCO}_{3}$ were characterized. Fig. 2 shows the XRD patterns of AC$\mathrm{CO}$ and AC-CC samples, wherein an almost amorphous structure can be detected, with the main peak at around $25^{\circ}$ that indicates the presence of some graphite. ${ }^{14)}$ The corresponding XRD patterns of AC-CC are also shown in Fig. 2. No matter what the morphologies of $\mathrm{CaCO}_{3}$ were, all the peaks can be indexed to calcite (JCPDS no. 05-0586). The sharp narrow diffraction peaks indicated that the as-prepared $\mathrm{CaCO}_{3}$ samples had good crystallinity for all $\mathrm{CaCO}_{3}$ morphologies. However, the crystalline form of calcite had changed slightly and revealed a slight difference, as reported previously. Moreover, the XRD pattern of the assynthesized sample in Fig. 2 illustrates characteristic peaks of $\mathrm{Ca}(\mathrm{OH})_{2}$, indicating that $\mathrm{Ca}(\mathrm{OH})_{2}$ with high crystallinity was successfully obtained. All the detected peaks with Miller indices (001), (100), (101), (102), (110), and (111) at $2 \theta$ values of $18.0,28.6,34.0,47.1,50.7$, and $54.3^{\circ}$, respectively, can be indexed to the hexagonal structure of $\mathrm{Ca}(\mathrm{OH})_{2}$ (JCPDS file 87-0315), with preferred orientation along the (101) plane.

The SEM images of the AC-CO and AC-CC samples are shown in Fig. 3. The surfaces of the samples have fairly similar morphologies, with cracks and voids present. The surfaces are heavily pitted, indicating that the samples are very porous. In addition, some nanoparticles (less than 500 $\mathrm{nm}$ in size) could be found on the surface of AC. The SEM images of the $\mathrm{CaCO}_{3}$ particles are also shown in Fig. 3. The results reveal spherical particles of sizes $\sim 300 \mathrm{~nm}$. To make it more persuasive, energy spectroscopy analysis was also performed to prove the existence of AC-CO and AC-CC (Fig. 4). Elemental carbon existed in relatively high amounts.

\subsection{Mechanical strength characteristics of ACs}

During operation and loading in the adsorption columns, the mechanical strength of the composite material is very significant for its packaging and manufacturing.

The measurements of crush strength are intended to provide an indication on the ability of AC to maintain its physical integrity during handling and use. Failure of the AC in a fixed bed causes maldistribution of fluid flow (liquid or gas) and a large pressure drop through the bed, which result in low efficiencies of the sorption processes. Activated carbons are porous and full of defects, dislocations, and discontinuities in their bulk phase. Activated carbons are also typically brittle materials and, therefore, their failure is due to brittle fracture. The data obtained in this work (Table 1) are in agreement with those reported in the literature. ${ }^{15)}$ The results show that mechanical strength for crushing the $\mathrm{AC}$ pellets increased with increasing pyrolysis temperature, from $4 \mathrm{MPa}$ at $400^{\circ} \mathrm{C}$ to $9.25 \mathrm{MPa}$ at $750^{\circ} \mathrm{C}$. This is due to the carbonization process, which increases in intensity with increasing temperature and leads to the uniformity of the structure into the resulting carbon that increases the strength.

\subsection{BET surface area and iodine absorption}

The BET surface areas and pore volumes of the ACs are summarized in Table 1. The surface area of the sample prepared from AC-CO or AC-CC is noticeably higher than the raw material AC (AC-Raw). The AC-CO or AC-CC sample produced $\mathrm{AC}$ with the highest surface area. The micropore volumes of the ACs produced from $\mathrm{Ca}(\mathrm{OH})_{2}$ and $\mathrm{CaCO}_{3}$ are also higher than that of AC-Raw. This shows that $\mathrm{Ca}(\mathrm{OH})_{2}$ or $\mathrm{CaCO}_{3}$ modification improves the microporosity of the $\mathrm{AC}$ produced. Moreover, AC-CO and AC-CC have demonstrated improved iodine sorption capacities (> 100\% mass gain) compared to AC powders with high specific areas (Fig. 4). The increased iodine sorption capacity observed in $20 \%$ AC$\mathrm{CO}$ and $15 \%$ AC-CC despite a relatively lower specific sur-

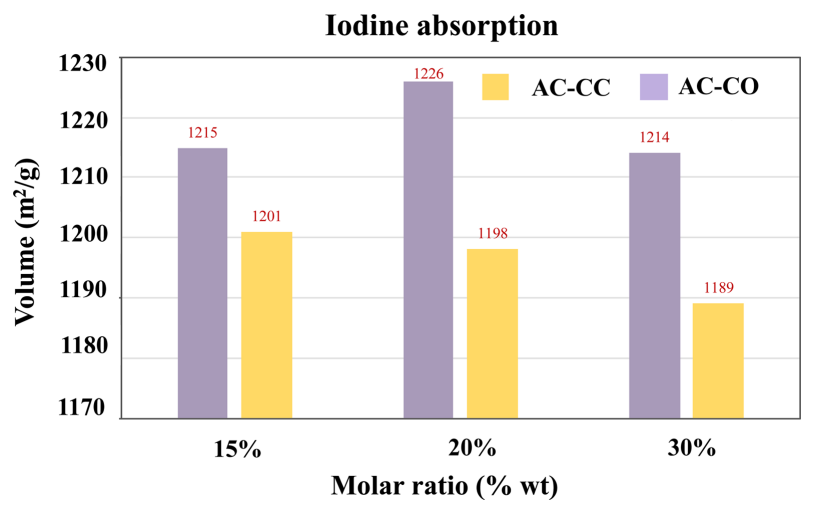

Fig. 4. Iodine absorption of AC-CO and AC-CC with different molar ratios.

Table 1. BET Surface Areas and Pore Size Distribution

\begin{tabular}{ccccc}
\hline Sample & $\begin{array}{c}\text { Mechanical strength } \\
(\mathrm{MPa})\end{array}$ & $\begin{array}{c}\text { BET surface area } \\
\left(\mathrm{m}^{2} / \mathrm{g}\right)\end{array}$ & $\begin{array}{c}\text { Pore volume } \\
(\mathrm{ml} / \mathrm{g})\end{array}$ & $\begin{array}{c}\text { Average pore diameter } \\
(\mathrm{nm})\end{array}$ \\
\hline $15 \%$ AC-CO & $9 \pm 2$ & 1426 & 0.464 & 1.90 \\
$20 \%$ AC-CO & $9 \pm 2$ & 1306 & 0.553 & 1.87 \\
$30 \%$ AC-CO & $9.25 \pm 2$ & 1257 & 0.534 & 1.93 \\
$15 \%$ AC-CC & $7 \pm 2$ & 1321 & 0.541 & 1.98 \\
$20 \%$ AC-CC & $8 \pm 2$ & 1257 & 0.557 & 1.86 \\
$30 \%$ AC-CC & $4 \pm 2$ & 1165 & 0.489 & 1.94 \\
\hline
\end{tabular}




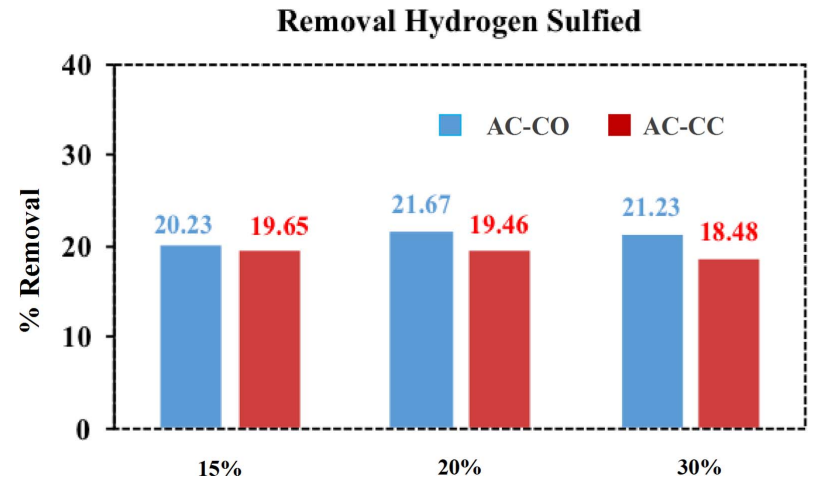

Fig. 5. Removal efficiencies of $\mathrm{H}_{2} \mathrm{~S}$ for 15, 20, and 30\% AC$\mathrm{CO}$ and $\mathrm{AC}-\mathrm{CC}$.

face area, compared to pristine AC, is indicative of a structural factor attributed to the pore shape and size of the highly porous AC.

\subsection{Removal efficiency of $\mathrm{H}_{2} \mathrm{~S}$}

The experiments focusing on the effect of mole ratio of $\mathrm{AC}$ $\mathrm{CO}$ or AC-CC on $\mathrm{H}_{2} \mathrm{~S}$ removal efficiency and selectivity were carried out. As shown in Fig. 5, the results indicate that irrespective of the mole ratio of AC-CO or AC-CC $(15,20$, or $30 \%$ ), the $\mathrm{H}_{2} \mathrm{~S}$ removal efficiencies of $30 \% \mathrm{AC}-\mathrm{CO}$ and $30 \%$ AC-CC are always higher than those of $15 \% \mathrm{AC}-\mathrm{CO}$ and $15 \%$ AC-CC. Surface area played a significant role in simultaneous absorption of $\mathrm{H}_{2} \mathrm{~S}$. Moreover, 30\% AC-CO showed the best absorption performance and maintained nearly $100 \% \mathrm{H}_{2} \mathrm{~S}$ removal efficiency within $30 \mathrm{~min}$. Both the removal efficiency and selectivity increased with the increase in the ratio.

\subsection{Ammonia gas removal efficiency}

The adsorption capacities of $\mathrm{NH}_{3}$ onto AC-CO or AC-CC (15, 20, and 30\%) were calculated by using the Langmuir and Freundlich adsorption equations. The Langmuir isotherm has the following form:

$$
\mathrm{q}_{\mathrm{e}}=\mathrm{q}_{\max }\left(\mathrm{K}_{\mathrm{L}} \mathrm{C}_{\mathrm{e}}\right) /\left(1+\mathrm{K}_{\mathrm{L}} \mathrm{C}_{\mathrm{e}}\right) \text {, }
$$

where $q_{\max }$ is the adsorption capacity of the adsorbent toward a specific solute and $\mathrm{K}_{\mathrm{L}}$ is the adsorption affinity, a parameter that measures how strongly the adsorbate attaches to the adsorbent. One of the advantages of using the Langmuir equation for representing adsorption equilibria data is that it reduces to Henry's law at very low concentrations and corresponds to limit saturation capacity.

Langmuir model is one of the most widely used isotherm

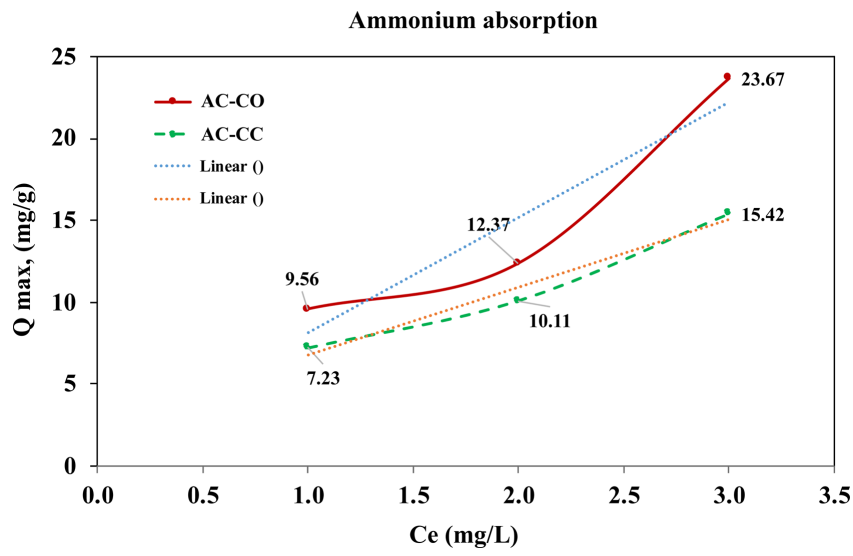

Fig. 6. Ammonium adsorption capacities of 15,20 , and $30 \%$, $\mathrm{AC}-\mathrm{CO}$ and $\mathrm{AC}-\mathrm{CC}$.

models for liquid phase adsorption data. In Fig. 6, the parameter $q_{\max }$ of the Langmuir equation represents the adsorption capacity of the adsorbent. The adsorption capacities of the adsorbents used in this study follow the order $30 \%$ AC-CO $>30 \%$ AC-CC $>20 \%$ AC-CO > 20\% AC-CC > $15 \%$ AC-CO $>15 \%$ AC-CC (Table 2). The mechanism of ammonium adsorption on 30\% AC-CO is mainly physical adsorption (Van der Waals interaction), since the surface area of AC-CO is lower compared to those of $15 \%$ and $20 \%$ AC-CO or AC-CC, therefore, the uptake amount of ammonium on $30 \% \mathrm{AC}-\mathrm{CO}$ or AC-CC is lower than that of the other adsorbents. Moreover, AC-CO has the highest adsorption capacity possibly due to its highest BET surface area and a more developed porous structure. During the thermal process of the preparation of the composite, $\mathrm{CO}_{2}$ gas has the role of an activating agent for AC-CO; at high temperatures, $\mathrm{CO}_{2}$ becomes a reactive gas, and oxidizes a fraction of AC$\mathrm{CO}$ in the composite structure, leading to opening of the existing pores and forming new micropores in the structure. With the increase in surface area and pore volume, the capability of the composite to attach more ammonium ions from the solution through Van der Waals forces also increased.

\section{6. $\mathrm{CO}_{2}$ adsorption capacity of ACs}

The $\mathrm{CO}_{2}$ adsorption capacities for different molar ratios (15\% and $20 \%$ ) of AC-calcium derivative are shown in Fig. 7. Fig. 7 and Table 3 present the $\mathrm{CO}_{2}$ adsorption capacities measured at different temperatures $\left(300-700^{\circ} \mathrm{C}\right)$ for the carbon activated for $3 \mathrm{~h}$ at $750^{\circ} \mathrm{C}$. The results from Fig. 7 show that the adsorption capacity increases rapidly with

Table 2. Langmuir Parameters for the Adsorption of Ammonium on 15, 20, and 30\% AC-CO and AC-CO

\begin{tabular}{cccccccc}
\hline \multirow{2}{*}{ Parameter } & \multicolumn{3}{c}{$15 \%$} & \multicolumn{3}{c}{$20 \%$} & \\
\cline { 2 - 7 } & AC-CO & AC-CC & AC-CO & AC-CC & AC-CO & AC-CC \\
\hline $\mathrm{q}_{\max }(\mathrm{mg} / \mathrm{g})$ & 9.56 & 7.23 & 12.37 & 10.11 & 23.67 & 15.42 \\
$\mathrm{~K}_{\mathrm{L}}(\mathrm{L} / \mathrm{mg})$ & 0.0232 & 0.0212 & 0.0501 & 0.0462 & 0.0738 & 0.0691 \\
$\mathrm{R}_{2}$ & 0.9834 & 0.9321 & 0.9832 & 0.9976 & 0.9913 & 0.9941 \\
\hline
\end{tabular}



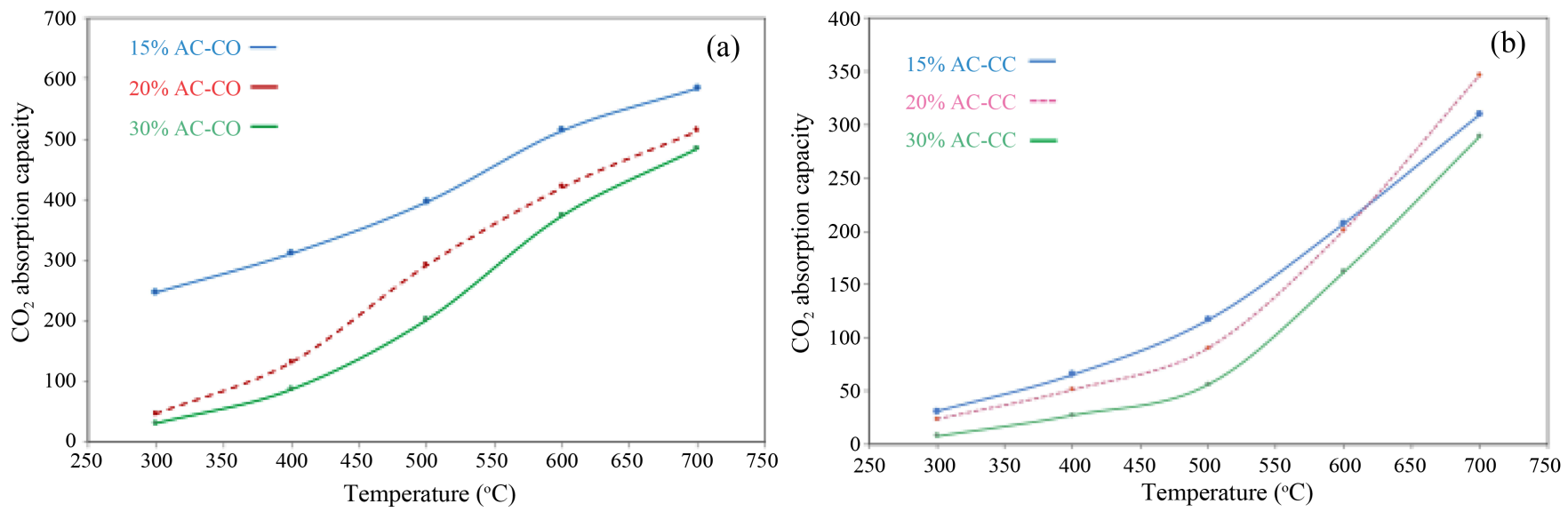

Fig. 7. $\mathrm{CO}_{2}$ adsorption capacities of $15-30 \%$ (a) AC-CO and (b) AC-CC.

Table 3. Carbon Dioxide Adsorption Capacity

\begin{tabular}{|c|c|c|c|c|}
\hline No. & Sample & $\begin{array}{c}\text { Temperature } \\
\left({ }^{\circ} \mathrm{C}\right)\end{array}$ & $\begin{array}{c}\mathrm{CO}_{2} \text { adsorption } \\
\text { capacity } \\
\text { (mg/g) }\end{array}$ & $\begin{array}{c}\mathrm{CO}_{2} \text { adsorption } \\
\text { capacity } \\
\text { (mmol/g) }\end{array}$ \\
\hline \multirow{5}{*}{1} & \multirow{5}{*}{$\begin{array}{c}15 \% \\
\mathrm{Ca}(\mathrm{OH})_{2}\end{array}$} & 300 & 246.517 & 5.603 \\
\hline & & 400 & 311.104 & 7.070 \\
\hline & & 500 & 396.440 & 9.010 \\
\hline & & 600 & 514.322 & 11.689 \\
\hline & & 700 & 584.979 & 13.295 \\
\hline \multirow{5}{*}{2} & \multirow{5}{*}{$\begin{array}{c}20 \% \\
\mathrm{Ca}(\mathrm{OH})_{2}\end{array}$} & 300 & 46.839 & 1.065 \\
\hline & & 400 & 131.725 & 2.994 \\
\hline & & 500 & 292.422 & 6.646 \\
\hline & & 600 & 420.693 & 9.561 \\
\hline & & 700 & 513.968 & 11.681 \\
\hline \multirow{5}{*}{3} & \multirow{5}{*}{$\begin{array}{c}30 \% \\
\mathrm{Ca}(\mathrm{OH})_{2}\end{array}$} & 300 & 30.980 & 0.704 \\
\hline & & 400 & 86.816 & 1.973 \\
\hline & & 500 & 201.729 & 4.585 \\
\hline & & 600 & 373.199 & 8.482 \\
\hline & & 700 & 484.510 & 11.012 \\
\hline \multirow{5}{*}{4} & \multirow{5}{*}{$\begin{array}{c}15 \% \\
\mathrm{CaCO}_{3}\end{array}$} & 300 & 30.784 & 0.670 \\
\hline & & 400 & 65.133 & 1.480 \\
\hline & & 500 & 116.656 & 2.651 \\
\hline & & 600 & 207.064 & 4.706 \\
\hline & & 700 & 309.462 & 7.033 \\
\hline \multirow{5}{*}{5} & \multirow{5}{*}{$\begin{array}{c}20 \% \\
\mathrm{CaCO}_{3}\end{array}$} & 300 & 23.551 & 0.535 \\
\hline & & 400 & 51.087 & 1.161 \\
\hline & & 500 & 90.217 & 2.050 \\
\hline & & 600 & 200.725 & 4.561 \\
\hline & & 700 & 346.377 & 7.872 \\
\hline \multirow{5}{*}{6} & \multirow{5}{*}{$\begin{array}{c}30 \% \\
\mathrm{CaCO}_{3}\end{array}$} & 300 & 7.536 & 7.536 \\
\hline & & 400 & 27.195 & 27.195 \\
\hline & & 500 & 56.029 & 56.029 \\
\hline & & 600 & 161.533 & 161.533 \\
\hline & & 700 & 288.663 & 288.663 \\
\hline
\end{tabular}

TCD Concentration vs. Time

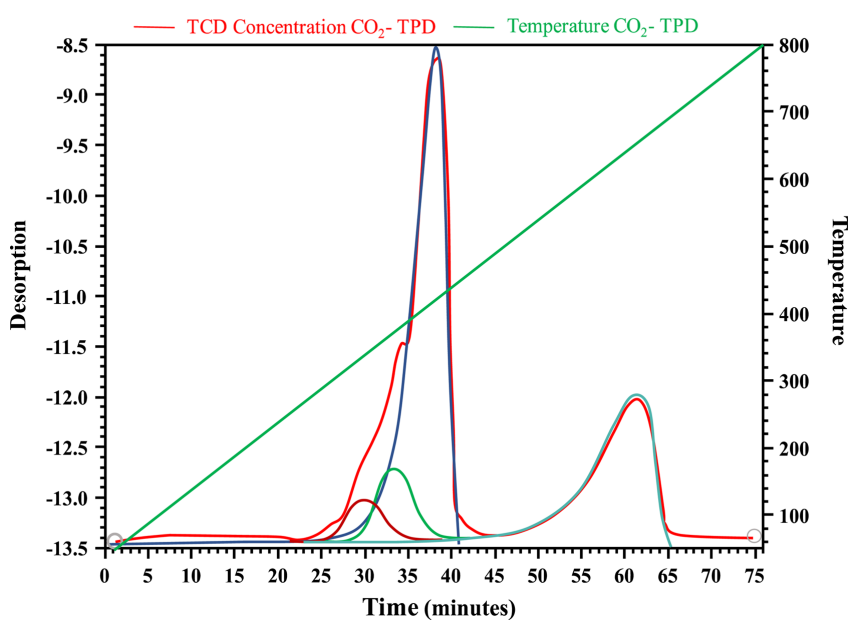

Fig. 8. Desorption amounts measured with TPD (TCD concentration vs. time).

increasing adsorption temperature. This is attributed to the typical process of physical adsorption, where both the surface adsorption energy and molecular diffusion rate increase with increasing temperature and, as a consequence, the adsorbed gas on the AC surface becomes unstable, resulting in the desorption of the adsorbed $\mathrm{CO}_{2}$ molecules (Fig. 8 and Table 4). However, the flue gas temperatures are typically up to $150^{\circ} \mathrm{C}$ and, therefore, it is necessary to develop sorbents that can be used at higher temperatures. ${ }^{7)}$ Accord-

Table 4. TCD Concentration vs. Time of Activated Carbon Samples

\begin{tabular}{cccc}
\hline $\begin{array}{c}\text { Peak } \\
\text { no. }\end{array}$ & $\begin{array}{c}\text { Temperature of } \\
\text { maximum }\end{array}$ & $\begin{array}{c}\text { Quantity } \\
(\mathrm{mmol} / \mathrm{g})\end{array}$ & $\begin{array}{c}\text { Peak concentration } \\
(\%)\end{array}$ \\
\hline 1 & 334.2544 & 0.98547 & 1.42456 \\
2 & 366.4523 & 1.13321 & 1.84250 \\
3 & 421.4523 & 6.55156 & 3.22451 \\
4 & 653.5786 & 3.91023 & 2.55057 \\
\hline
\end{tabular}


ingly, in this study, the surface of $\mathrm{AC}$ was treated with $\mathrm{Ca}(\mathrm{OH})_{2}$ and $\mathrm{CaCO}_{3}$ at high temperatures in an attempt to improve its $\mathrm{CO}_{2}$ adsorption capacity mainly at higher temperatures.

\section{Conclusions}

Activated carbon pellets were synthesized with $\mathrm{Ca}(\mathrm{OH})_{2}$ and $\mathrm{CaCO}_{3}$, which were used in the adsorption of $\mathrm{NH}_{3}, \mathrm{CO}_{2}$, and $\mathrm{H}_{2} \mathrm{~S}$ from polluted air. These pellets show high BET surface areas and mesoporous volumes. The AC pellets combined with $\mathrm{Ca}(\mathrm{OH})_{2}$ and $\mathrm{CaCO}_{3}$ showed increased surface area and large volume with micropores and mesopores compared with the carbon pellets synthesized without $\mathrm{Ca}(\mathrm{OH})_{2}$ or $\mathrm{CaCO}_{3}$. The weight ratios of the mixtures and the heat-treatment temperature have obvious effects on the formation and pore structures of the resulting carbon pellets. The effect of different treatment conditions such as adsorbent dosage on toxic gas removal efficiency was studied by experimental design. This study suggests that AC pellets combined with $\mathrm{Ca}(\mathrm{OH})_{2}$ and $\mathrm{CaCO}_{3}$ can be considered as ideal adsorbents for $\mathrm{NH}_{3}, \mathrm{CO}_{2}$, and $\mathrm{H}_{2} \mathrm{~S}$ removal from polluted air owing to their low cost, high safety, and good adsorption efficiency.

\section{Acknowledgments}

This work (grant no. C0510655) was supported by Business for Cooperative R\&D between Industry, Academy, and Research Institute funded by the Ministry of SMEs and Startups in 2017.

\section{REFERENCES}

1. Y. G. Yu, D. K. Ning, and L. G. Qian, "The First-Principle Calculation of $\mathrm{H}_{2} \mathrm{~S}$ Adsorption and Decomposition on the ZnO (0001) Surface," Chin. J. Struct. Chem., 29 [8] 113946 (2010).

2. T. Siciliano, E. Filippo, A. Genga, G. Micocci, M. Siciliano, and A. Tepore, "Single-Crystalline Te Microtubes: Synthesis and NO Gas Sensor Application," Sens. Actuators, B, 142 [1] 185-90 (2009).

3. J. K. Razna, P. Nowicki, M. Wiśniewska, A. NosalWiercińska, and R. Pietrzak, "Thermal and Physicochemical Properties of Phosphorus-Containing Activated Carbons Obtained from Biomass," J. Taiwan Inst. Chem. Eng., 80 1006-13 (2017).
4. A. Kaushik, S. Basu, K. Singh, V. S. Batra, and M. Balakrishnan, "Activated Carbon from Sugarcane Bagasse Ash for Melanoidins Recovery," J. Environ. Manage., 200 29-34 (2017).

5. G. Lytras, C. Lytras, D. Argyropoulou, N. Dimopoulos, G. Malavetas, and G. Lyberatos, "A Novel Two-Phase Bioreactor for Microbial Hexavalent Chromium Removal from Wastewater," J. Hazard. Mater., 336 41-51 (2017).

6. A. Alexopoulos, S. Plessas, Y. Kourkoutas, C. Stefanis, S. Vavias, C. Voidarou, I. Mantzourani, and E. Bezirtzoglo, "Experimental Effect of Ozone upon the Microbial Flora of Commercially Produced Dairy Fermented Products," Int. J. Food Microbiol., 246 5-11 (2017).

7. E. Belashova, S. Mikhaylin, N. Pismenskaya, V. Nikonenko, and L. Bazinet, "Impact of Cation-Exchange Membrane Scaling Nature on the Electrochemical Characteristics of Membrane System," Sep. Purif. Technol., 189 441-48 (2018).

8. A. Colombo, M. Geiker, H. Justnes, R. A. Lauten, and K. De Weerdt, "On the Mechanisms of Consumption of Calcium Lignosulfonate by Cement Paste," Cem. Concr. Res., 98 19 (2017).

9. I. G. Richardson and S. Li, "Composition and Structure of an 18-Year-Old $5 \mathrm{M} \mathrm{KOH-Activated} \mathrm{Ground} \mathrm{Granulated}$ Blast-Furnace Slag Paste," Constr. Build. Mater., 168 404-11 (2018).

10. M. Tarbe, H. de Pomyers, L. Mugniera, D. Bertin, T. Ibragimov, D. Gigmes, and K. Mabrouk, "Gram-Scale Purification of Aconitine and Identification of Lappaconitine in Aconitum Karacolicum," Fitoterapia, 120 85-92 (2017).

11. R. Roth, J. Schoelkopf, J. Huwyler, and M. Puchkov, "Functionalized Calcium Carbonate Microparticles for the Delivery of Proteins," Eur. J. Pharm. Biopharm., 122 96103 (2018)

12. J. G. Jang, H. J. Kim, S. M. Park, and H. K. Lee, "The Influence of Sodium Hydrogen Carbonate on the Hydration of Cement," Constr. Build. Mater., 94 746-49 (2015).

13. J. G. Jang and H. K. Lee, "Effect of Fly Ash Characteristics on Delayed High-Strength Development of Geopolymers," Constr. Build. Mater., 102 260-69 (2016).

14. E. Sakaiand and M. Daimon, "Morpology and Formation of Calcium Aluminate Hydrates," Inorg. Mater., 2 [258] 375-82 (1995).

15. H. M. Lee, J. Y. Hwang, J. H. Lee, B. S. Son, and J. H. Oh, "The Effect of Chloride Additives and $\mathrm{pH}$ on Direct Aqueous Carbonation of Cement Paste," J. Mineral. Soc. Korea, 28 [1] 39-49 (2015). 